\title{
Correction to: Extraction and recovery response of Penaeus indicus chitosan against Aeromonas hydrophila Ah17 infected snakehead murrel Channa striata
}

\author{
Vignesh Samayanpaulraj ${ }^{1}$ - Vijay Velu ${ }^{1}$ - Muthukumar Sivaramapillai ${ }^{1}$ • \\ Krishnaveni Govindaraj ${ }^{1}$ - Ramesh Uthandakalaipandiyan ${ }^{1}$
}

Published online: 28 December 2019

(C) Springer Nature Switzerland AG 2019

\section{Correction to: Aquaculture International https://doi.org/10.1007/s10499-019-00481-4}

The original version of this article unfortunately contains incorrect equation under the material and method section, in chitosan yield methods part of the formula.

The corrected equation is shown below.

$$
\% \text { Yield }=\text { weight } \text { of chitosan/weight of exoskeleton } \times 100
$$

The original article has been corrected.

Publisher's Note Springer Nature remains neutral with regard to jurisdictional claims in published maps and institutional affiliations.

The online version of the original article can be found at https://doi.org/10.1007/s10499-019-00481-4

\section{Ramesh Uthandakalaipandiyan}

ramesh.biological@mkuniversity.org

Vignesh Samayanpaulraj genovignesh@gmail.com

Vijay Velu

vijaymsu1989@gmail.com

Muthukumar Sivaramapillai

smk2882@gmail.com

Krishnaveni Govindaraj

krishbioit@gmail.com

1 Department of Molecular Biology, School of Biological Sciences, Madurai Kamaraj University, Madurai, Tamil Nadu 21, India 